\title{
Microbial uptake of low-molecular-weight organic substances out-competes sorption in soil
}

\author{
H. FisCHER ${ }^{a, b}$, J. INGWERSEN ${ }^{c}$ \& Y. KUZYAKOV \\ ${ }^{\mathrm{a}}$ Institute of Soil Science and Land Evaluation, Soil Science and Petrography, University of Hohenheim, Stuttgart, Germany, ${ }^{\mathrm{b}}$ Department \\ of Agroecosystem Research, BayCEER, University of Bayreuth, Bayreuth, Germany and ${ }^{\mathrm{c}}$ Institute of Soil Science and Land Evaluation, \\ Biogeophysics, University of Hohenheim, Stuttgart, Germany
}

\begin{abstract}
Summary
Low-molecular-weight organic substances (LMWOS) such as amino acids, sugars and carboxylates, are rapidly turned over in soil. Despite their importance, it remains unknown how the competition between microbial uptake and sorption to the soil matrix affects the LMWOS turnover in soil solution. This study describes the dynamics of LMWOS fluxes $(10 \mu \mathrm{M})$ in various pools (dissolved, sorbed, decomposed to $\mathrm{CO}_{2}$ and incorporated into microbial biomass) and also assesses the LMWOS distribution in these pools over a very wide concentration range $(0.01-1000 \mu \mathrm{M})$. Representatives of each LMWOS group (glucose for sugars, alanine for amino acids, acetate for carboxylates), uniformly ${ }^{14} \mathrm{C}$-labelled, were added to sterilized or nonsterilized soil and analysed in different pools between 1 minute and 5.6 hours after addition. LMWOS were almost completely taken up by microorganisms within the first 30 minutes. Surprisingly, microbial uptake was much faster than the physicochemical sorption (estimated in sterilized soil), which needed 60 minutes to reach quasi-equilibrium for alanine and about 400 minutes for glucose. Only acetate sorption was instantaneous. At a concentration of $100 \mu \mathrm{M}$, microbial decomposition after 4.5 hours was greater for alanine $(76.7 \pm 1.1 \%)$ than for acetate $(55.2 \pm 0.9 \%)$ or glucose $(28.5 \pm 1.5 \%)$. In contrast, incorporation into microbial biomass was greater for glucose $(59.8 \pm 1.2 \%)$ than for acetate $(23.4 \pm 5.9 \%)$ or alanine $(5.2 \pm 2.8 \%)$. Between 10 and $500 \mu \mathrm{M}$, the pathways of the three LMWOS changed: at $500 \mu \mathrm{M}$, alanine and acetate were less mineralized and more was incorporated into microbial biomass than at $10 \mu \mathrm{M}$, while glucose incorporation decreased. Despite the fact that the LMWOS concentrations in soil solution were important for competition between sorption and microbial uptake, their fate in soil is mainly determined by microbial uptake and further microbial transformations. For these substances, which represent the three main groups of LMWOS in soil, the microbial uptake out-competes sorption.
\end{abstract}

\section{Introduction}

Low-molecular-weight organic substances (LMWOS), such as amino acids, sugars or carboxylates, are released into soil by root exudation (Kraffczyk et al., 1984) or by plant and microorganism residue decomposition. As part of the soluble fraction, LMWOS can be rapidly incorporated and used by soil microorganisms and by plants (Kuzyakov \& Jones, 2006). Biernath et al. (2008), however, found that the relevance of direct uptake of amino acids, carboxylates and sugars by plants is very small; it can be disregarded with respect to the diffusive and dispersive LMWOS fluxes. In contrast to plant uptake, the LMWOS incorporation into microorganisms and their subsequent mineralization to $\mathrm{CO}_{2}$

Correspondence: H. Fischer. E-mail: Holger.Fischer@uni-hohenheim.de. Received 19 August 2009, revised version accepted 09 March 2010 is one of the dominating processes and strongly depends on various factors such as concentration, temperature, soil texture, composition of clay minerals and sesquioxides. The fast uptake and utilization of LMWOS by microorganisms results in intensive turnover and short half-lives. These range from less than 1 minute to about 40 minutes in soil solution (e.g. Hill et al., 2008; Schneckenberger et al., 2008) and from about 1 hour to a few days in microorganisms (e.g. Kuzyakov \& Demin, 1998; Jones \& Shannon, 1999). However, the half-lives of LMWOS sorbed to the soil matrix can be considerably longer (about 100 days) (Kuzyakov \& Demin, 1998). In addition to incorporation and sorption, LMWOS are subject to leaching. All these concurrent processes lead to removal of LMWOS from the soil solution and therefore to small concentrations of approximately $0.1-100 \mu \mathrm{M}$ for free amino acids (e.g. Fischer et al., 2007), 0.1-1000 $\mu \mathrm{M}$ 
for carboxylates (van Hees et al., 2002; Fischer et al., 2010) and approximately 2-10 $\mu \mathrm{M}$ for sugars (Fischer et al., 2007).

Sorption by soil particles can protect LMWOS from microbial degradation to some extent (Jones \& Edwards, 1998; van Hees et al., 2002). Abundant literature is available about sorption of LMW carboxylates (see reviews of Jones, 1998; Jones et al., 2003). Most previous studies, however, have investigated competitive sorption of carboxylates under concentrations much greater than those commonly found in soil (5-30 mM) (e.g. Pegoraro et al., 2005). Others have investigated sorption onto natural or artificial minerals such as $\mathrm{Al}(\mathrm{OH})_{\mathrm{x}}$-montmorillonite or $\mathrm{Al}(\mathrm{OH})_{\mathrm{x}}$ (De Cristofaro et al., 2000) instead of a natural soil matrix. Information on sorption of carbohydrates and amino acids is scarce. Only Jones \& Edwards (1998) have compared degradation and sorption of citrate with glucose, and Jones \& Hodge (1999) investigated the same processes for the three differently charged amino acids (i.e. glutamate, glycine and lysine). Results from both studies indicated that the presence of soil or mineral phases reduced LMWOS bioavailability, probably because of sorption to the soil matrix. The extent of bioavailability reduction depended on the substance as well as on the matrix provided for sorption. No study has investigated the microbial and physico-chemical processes to which LMWOS (with representatives of all amino acids, carbohydrates and carboxylates) are subjected in the same experiment and compared which of the processes is dominant. Moreover, the LMWOS removal from soil solution by uptake by microorganisms was usually not determined directly but merely by monitoring the evolution of $\mathrm{CO}_{2}$ from the added substances. Certainly, there will be a time lag between uptake and decomposition to $\mathrm{CO}_{2}$, which could not be assessed with this type of study.

As microbial uptake and sorption are competing, simultaneous processes in soil, our aim was to quantify sorption and microbial uptake of certain LMWOS under identical experimental conditions in concentration ranges relevant for the rhizosphere where the LMWOS are continuously produced. This study therefore describes the dynamics of fluxes of LMWOS into various pools (dissolved, adsorbed, decomposed, and incorporated into microbial biomass) at rhizosphere-relevant concentrations (10 $\mu \mathrm{M})$ and assesses LMWOS distribution in these pools depending on the range of concentrations normally relevant for soil solutions $(0.01-1000 \mu \mathrm{M})$. Alanine, glucose and acetate were chosen as representatives of amino acids, sugars and carboxylates, respectively. The experiments were conducted with and without sterilization in order to distinguish between sorption, microbial uptake and decomposition.

\section{Materials and methods}

\section{Soil}

Samples were taken from an Ap horizon (the first $10 \mathrm{~cm}$ ) of a Haplic Luvisol (IUSS Working Group WRB, 2007) from Heidfeldhof near Hohenheim University, Germany. The soil had the following characteristics: $\mathrm{pH} 6.9$, total $\mathrm{C}$ content $1.5 \%$, and
$\mathrm{CEC}_{\text {pot }} 210 \mathrm{mmol}_{\mathrm{c}} \mathrm{kg}^{-1}$. The texture was $22.6 \%$ clay, $62.9 \%$ silt and $14.5 \%$ sand (silt loam). The soil was air-dried $\left(25^{\circ} \mathrm{C}\right.$, 96 hours) and sieved ( $<2 \mathrm{~mm}$ ) to remove roots and to homogenize the sample. The soil was re-moistened 24 hours prior to the addition of the treatments to activate microbial biomass.

\section{Chemicals and radiochemical analysis}

Alanine, glucose and sodium acetate were uniformly labelled with ${ }^{14} \mathrm{C}$ (Sigma-Aldrich, Taufkirchen, Germany). These substances were mixed with a certain quantity of the respective unlabelled substance. Regardless of the total amount of LMWOS addition, an activity of $5 \mathrm{kBq}{ }^{14} \mathrm{C}$ was used in each experimental tube.

${ }^{14} \mathrm{C}$ from the labelled substances was analysed in soil solution and in soil (considered to be sorbed to the soil matrix and/or incorporated into microbial biomass). ${ }^{14} \mathrm{C}$ in soil solution was determined by adding $1 \mathrm{ml}$ to a scintillation cocktail ( $4 \mathrm{ml}$, EcoPlus, Roth Company, Karlsruhe, Germany) and measuring the activity of the sample with a scintillation counter (Wallac 1409; EG\&G Ltd, Milton Keynes, UK). ${ }^{14} \mathrm{C}$ in the soil matrix was measured after discarding the supernatant and drying the soil $\left(80^{\circ} \mathrm{C}, 24\right.$ hours). After drying, total carbon in the soil was converted into $\mathrm{CO}_{2}$ via an OX 400 Biological Oxidizer (Harvey Instruments Corp., Hillsdale, NJ, USA). The $\mathrm{CO}_{2}$ evolved from the oxidation of soil $\mathrm{C}$ was trapped in an absorber liquid and subsequently analysed for its ${ }^{14} \mathrm{C}$ activity by liquid scintillation. As the recovery of ${ }^{14} \mathrm{C}$ in all pools in sterilized treatments was nearly $100 \%$, the $\mathrm{CO}_{2}$ from the decomposition of LMWOS by microorganisms in non-sterilized treatments was calculated from the difference between total ${ }^{14} \mathrm{C}$ measured in soil and solution and $100 \%$ of the ${ }^{14} \mathrm{C}$ addition.

\section{Experimental setup}

The study consisted of two experiments. The aim of the first experiment was to describe the dynamics of LMWOS removal from soil solution and to determine the time needed to reach equilibrium between the pools defined here as 'dissolved', 'adsorbed' and 'incorporated into microbial biomass'. The aim of the second experiment was to assess the LMWOS distribution in these pools depending on the initial solution concentration.

For both experiments, $2.25 \mathrm{ml}$ of deionized water with one of the model substances were added to a $15-\mathrm{ml}$ centrifuge tube (VWR, Bruchsal, Germany) containing $1 \mathrm{~g}$ soil. Three treatments were tested within the experiments: (i) without sterilization, (ii) sterilized with $25 \mu \mathrm{CHCl}_{3}$ and (iii) sterilized with $250 \mu \mathrm{l} 500 \mu \mathrm{M}$ $\mathrm{NaN}_{3}$ and $500 \mu \mathrm{M} \mathrm{HgCl} \mathrm{Hg}_{2}$. To the incubation tubes of treatments (i) $250 \mu \mathrm{l}$ deionized water was added to $1 \mathrm{~g}$ soil in the incubation tubes 24 hours prior to the LMWOS in order to activate microorganisms. The small water volume of $250 \mu \mathrm{l}$ does not induce soil dispersion, but is sufficient to make organics and nutrients available for microorganisms.

For the first experiment, the LMWOS end-concentration was $10 \mu \mathrm{M}$ (in $2.5 \mathrm{ml}$ ). The tubes were shaken by hand for 1 minute. 
They were then centrifuged for 10 minutes at $1500 \mathrm{~g}$. In preliminary experiments, this force did not cause any adverse effect such as disruption, on microbial cells. Samples of $50 \mu \mathrm{l}$ were taken from the supernatant. Subsequently, the tubes were shaken at 150 revolutions per minute on a reciprocating shaker (KS 10, Bühler, Tübingen, Germany) until the next sampling time, when the same sampling procedure (centrifugation) was repeated. The last samples were taken 300 minutes after LMWOS addition to the soil. Centrifugation time was not counted as mixing time.

In the second experiment, the mixing time was fixed at 200 minutes and LMWOS concentrations were varied from 0.01 to $1000 \mu \mathrm{M}$ (corresponding to $0.025-2.5 \mathrm{mmol} \mathrm{kg}-1$ soil). As microbial biomass $\mathrm{C}$ in this soil was approximately $0.021-0.031 \%$ (Werth et al., 2006), the LMWOS addition of $1000 \mu \mathrm{M}$ corresponds to $60-80 \%$ (glucose), 30-40\% (alanine) and 20-28\% (acetate) of microbial $C$.

\section{Calculation of distribution in pools}

To describe the distribution of the added substance between the pools, we expressed this as percentage of the added amount. However, to describe the sorption parameters, as well as to reflect the changes as depending on LMWOS concentration, we used absolute concentrations as $\mu \mathrm{m}$ or $\mu \mathrm{mol} \mathrm{kg}{ }^{-1}$. Please note, however, that the same pools are marked with identical abbreviations. The units for the respective parameters are always presented to simplify the understanding.

The ${ }^{14} \mathrm{C}$ activity was analyzed in soil and soil solution of sterilized and non-sterilized samples. The distribution of the labelled LMWOS is shown by the recovery of ${ }^{14} \mathrm{C}$ activity (\% of added ${ }^{14} \mathrm{C}$ ). Under sterile conditions, total applied ${ }^{14} \mathrm{C}$ activity $\left(C_{\mathrm{T}}=100 \%\right)$ was distributed between the soil solution phase $\left(C_{\mathrm{L}}\right)$ and the sorbed phase $\left(C_{\mathrm{S}}\right)$ :

$$
C_{\mathrm{T}}=C_{\mathrm{L}}+C_{\mathrm{S}}
$$

where $C_{\mathrm{L}}$ and $C_{\mathrm{S}}$ are calculated as percentages of added amount. The relationship between $C_{\mathrm{L}}(\mu \mathrm{M})$ and $C_{\mathrm{S}}\left(\mu \mathrm{mol} \mathrm{kg}{ }^{-1}\right)$ was described by a Freundlich isotherm:

$$
C_{\mathrm{S}}=k_{f} * C_{\mathrm{L}}^{\mathrm{m}},
$$

where $k_{f}=$ Freundlich coefficient $\left(\mu \mathrm{mol}{ }^{1-\mathrm{m}} \mathrm{litre}^{\mathrm{m}} \mathrm{kg}^{-1}\right)$ and $\mathrm{m}=$ Freundlich exponent.

In non-sterilized samples, ${ }^{14} \mathrm{C}$ in the soil or in solution can be either the initial LMWOS added or a dissolved decomposition product of the LMWOS. Microorganisms affect $C_{\mathrm{L}}$ and the amount of ${ }^{14} \mathrm{C}$ measured in the non-sterilized soil matrix $\left({ }^{N} C_{\mathrm{M}}\right)$. When pool sizes do not change further, ${ }^{N} C_{\mathrm{M}}(\%)$ is the sum of LMWOS adsorbed to the soil $\left({ }^{N} C_{\mathrm{S}}(\%)\right)$ and incorporated into microbial biomass $\left({ }^{N} C_{\mathrm{B}}(\%)\right)$ :

$$
{ }^{N} C_{\mathrm{M}}={ }^{N} C_{\mathrm{S}}+{ }^{N} C_{\mathrm{B}}
$$

We assume that the parameters of the Freundlich sorption isotherm calculated on the basis of equilibrium concentration under sterile conditions can be transferred to non-sterile conditions. Microorganisms have little direct effect on sorption of ${ }^{N} C_{\mathrm{S}}$ as they occupy less than $5 \%$ of the soil's surface (Nannipieri et al., 2003). As these sorption parameters were calculated for sterile conditions where no decomposition took place, ${ }^{14} \mathrm{C}$ from metabolites did not have to be taken into account. Thus, ${ }^{N} C_{\mathrm{S}}$ depends on the solution concentration in non-sterilized samples $\left({ }^{N} C_{\mathrm{L}}\right)$ and was determined with the Freundlich relationship as in Equation (2). By subtracting ${ }^{N} C_{\mathrm{S}}(\%)$ from ${ }^{N} C_{\mathrm{M}}(\%)$, the fraction incorporated into the microbial biomass $\left({ }^{N} C_{\mathrm{B}}\right.$, (\%)) was calculated.

${ }^{14} \mathrm{C}$ not recovered in non-sterilized samples was attributed to a loss of $\mathrm{CO}_{2}$ from complete microbial decomposition of the added LMWOS (RESPIR, (\%)):

$$
\text { RESPIR }=C_{\mathrm{T}}-{ }^{N} C_{\mathrm{M}}-{ }^{N} C_{\mathrm{L}}
$$

\section{Description of dynamics}

The dynamics of sorption of organic compounds to soil was described according to a 'two-stage one-rate' model (Streck et al., 1995). This model contains two sub-domains for sorption. They are characterized by different accessibilities. The first sub-domain (S1) is in direct exchange with the concentration in solution and is described by a Freundlich isotherm (as in Equation (2)). The exchange between $S 1$ and the second sorption domain $\left(S_{2}\right)$ is assumed to be rate-limited:

$$
(1-f) \frac{\partial S_{2}}{\partial t}=\alpha\left(S_{1}-S_{2}\right)
$$

where $S_{2}\left(\mu \mathrm{mol} \mathrm{kg}{ }^{-1}\right)$ denotes the sorbed LMWOS in the second sub-domain, $f$ stands for the fraction of $S_{1}$ sorption sites and $\alpha$ is the rate coefficient of sorption $\left(\right.$ minute ${ }^{-1}$ ). When the concentrations of both sub-domains are equal, the system is in equilibrium. Thus, concentrations of $S_{1}$ and $S_{2}$ do not change further and the net transport from $S_{1}$ to $S_{2}$ over time is zero. Equilibrium between the sorbed and the dissolved phase is reached when the fluxes of sorption and desorption occur at the same rate and both pools (sorbed to the soil matrix and dissolved in the soil solution) do not further change. At this state, the total sorbed amount $\left(C_{\mathrm{S}}\right)$ can be described with a Freundlich isotherm (Equation (2)) from the soil solution concentration $\left(C_{\mathrm{L}}\right) . C_{\mathrm{S}}$ is the sum of $S_{1}$ and $S_{2}$ weighted according to f:

$$
\text { f } S_{1}+\left(1-\text { f) } S_{2}=C_{\mathrm{S}}\right. \text {, }
$$

where $S_{1}, S_{2}$ and $C_{\mathrm{S}}$ are expressed as $\mu \mathrm{mol} \mathrm{kg} \mathrm{kg}^{-1}$. To determine the goodness of fit, the modelling efficiency (EF) was used as defined by Loague \& Green (1991):

$$
E F=1-\frac{\sum_{n}^{i=1}\left(P_{i}-O_{i}\right)^{2}}{\sum_{n}^{i=1}\left(O_{i}-\bar{O}\right)^{2}},
$$


where $P_{i}=$ predicted values, $O_{\mathrm{i}}=$ observed values, $\mathrm{n}=$ number of samples and $\bar{O}=$ average of observed data.

The Freundlich sorption equation parameters were fitted to the experimental data of the sterilized treatment in the second experiment. The experimentally determined parameters (including the Freundlich exponent (m)) were used as input for the 'two-stage one rate' model and afterwards compared with the k-value.

The total added LMWOS were distributed between two pools: that remaining in soil solution $\left({ }^{N} C_{\mathrm{L}}\right)$ and that removed from soil solution by sorption to the soil matrix and uptake into microorganisms. A single first-order kinetic equation with horizontal asymptote was fitted to experimental data of the time experiment to determine the rate of removal from the solution pool:

$$
{ }^{N} C_{\mathrm{L}}(t)={ }^{N} C_{\mathrm{L}}+\left(C_{\mathrm{T}}-{ }^{N} C_{\mathrm{L}}\right) \mathrm{e}^{-u t},
$$

where ${ }^{N} C_{\mathrm{L}}(t)={ }^{14} \mathrm{C}$ in soil solution at time $t(\%),{ }^{N} C_{1}=$ dissolved ${ }^{14} \mathrm{C}$ at the end of the experiment $(\%), C_{\mathrm{T}}={ }^{14} \mathrm{C}$ added to soil samples $(=100 \%), u=$ uptake rate $\left(\right.$ minute $\left.^{-1}\right)$, and $t=$ time (minutes).

The half-life time of removal (microbial uptake and sorption) of the LMWOS from the soil solution was calculated by:

$$
t_{0.5}=\frac{\ln 2}{u} .
$$

\section{Statistics}

The experiments were conducted in triplicate. All displayed data are means \pm standard errors. The significance of differences between concentrations was tested by one-way ANOva. When the test for homogeneity of variances was positive the post hoc test LSD was used, otherwise, Tamhane's T2 was applied. Recovery in all sterilized samples varied from 91.1 to $120.2 \%$. If not stated otherwise, data are presented as \% of recovery.

\section{Results}

\section{Estimation of equilibration period}

Under sterile conditions the added LMWOS may remain in the solution or be sorbed onto the soil matrix. In the non-sterilized samples, the LMWOS can also be taken up by microorganisms and incorporated into the cells, or be decomposed to $\mathrm{CO}_{2}$.

In sterilized samples, acetate sorption was very fast: acetate ${ }^{14} \mathrm{C}$ activity did not change after 28 minutes and remained constant at $18 \%$ of the added ${ }^{14} \mathrm{C}$ (this corresponds to $82 \%$ of the ${ }^{14} \mathrm{C}$ remaining in the solution) from the first sampling until the end of the experiment (Figure 1). In contrast, sorption of alanine and glucose was much slower. For alanine, the equilibrium between the adsorbed and dissolved phases was reached approximately 60 minutes after the treatments were added. Results from the 'twostage one-rate' model suggest that equilibrium of glucose sorption was reached after about 400 minutes. The kinetic sorption model
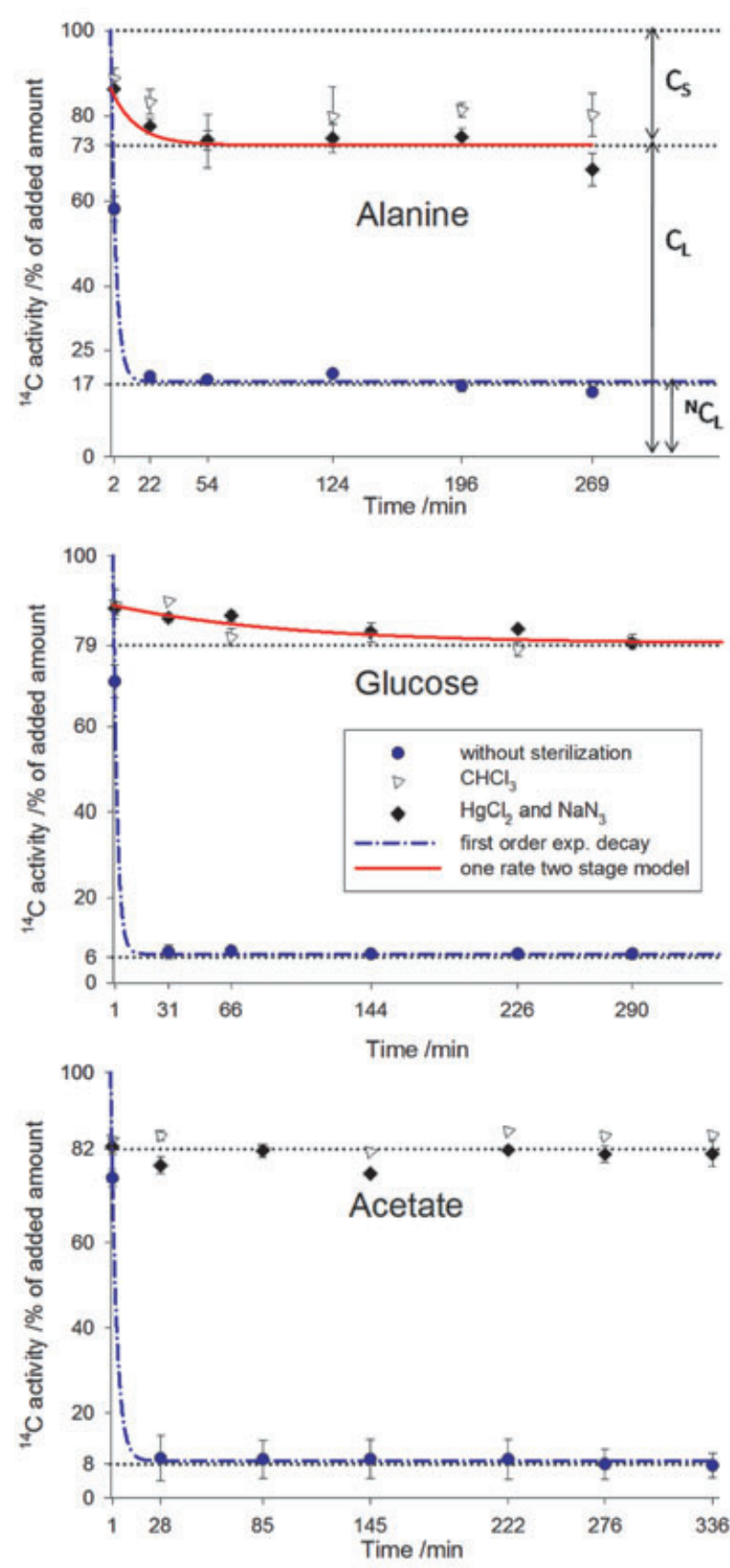

Figure $1{ }^{14} \mathrm{C}$ activity (\% of added ${ }^{14} \mathrm{C}$ ) of alanine, glucose and acetate in soil solution at $10 \mu \mathrm{M}$ with $\left(C_{\mathrm{L}}\right)$ and without $\left({ }^{N} C_{\mathrm{L}}\right)$ sterilization. Experimental points (means $\pm \mathrm{SE}, \mathrm{n}=3$ ) and model lines fitted on the basis of exponential decay $\left({ }^{N} C_{\mathrm{L}}\right)$ or 'two-stage one-rate' models $\left(C_{\mathrm{L}}\right)$. For acetate, no parameters for the 'two-stage one-rate' model were fitted.

describes the experimental data for alanine and glucose quite well (see modelling efficiency in Table 2). Moreover, optimized $k_{f}$ values were concordant with the $k_{f}$ values obtained from the concentration experiment (see later), at least for alanine. 
Table 1 Parameters of the first order kinetics with horizontal asymptote (Equation (8)) describing microbial uptake of added LMWOS: dissolved ${ }^{14} \mathrm{C}$ at equilibrium $\left({ }^{N} C_{\mathrm{L}}\right)(\%)$, uptake rate (u) $\left(\right.$ minute $\left.{ }^{-1}\right)$, LMWOS halflife $\left(\mathrm{t}_{0.5}\right)$ was calculated from u (Equation (9)). Modelled values are given $\pm \mathrm{SE}$

\begin{tabular}{llll}
\hline Substance & ${ }^{\mathrm{n}} \mathrm{C}_{\mathrm{L}}$ & $\mathrm{u}$ & $\mathrm{t}_{0.5}$ \\
\hline Alanine & $17.6 \pm 0.6$ & $0.4 \pm 2.0$ & 2.0 \\
Glucose & $06.7 \pm 0.4$ & $0.5 \pm 462.6$ & 1.5 \\
Na-acetate & $08.7 \pm 1.0$ & $0.3 \pm 7.1$ & 2.2 \\
\hline
\end{tabular}

The portion of absorbed alanine at equilibrium was greater $(26.9 \pm 1.2 \%)$ than that of glucose $(20.6 \pm 0.7 \%)$ or acetate $(18.1 \pm 1.2 \%)$ (Figure 1). Differences in the extent of sorption were only significant between alanine and Na-acetate $(P<0.05$; Tamhane's T2).

Microbial uptake of alanine, glucose and acetate was completed by the second sampling (22-31 minutes after the start) and thus was faster than sorption of alanine and glucose under sterile conditions. The first-order decay model (Equation (8)) led to half-life times for LMWOS in non-sterile soil solution from 1.5 to 2.2 (Table 1). These times were so short that only a few measurements could be performed to validate the parameters. Consequently, standard errors for $\mathrm{r}$ (and thus for $\mathrm{t}_{0.5}$ ) are very large.

At the end of the experiment, 4.5 hours after substance addition, solution concentrations did not change further. At this time, soil solution concentrations under non-sterile conditions $\left({ }^{N} C_{\mathrm{L}}\right)$ of $6.7 \pm 1.1 \%$ for glucose and $8.7 \pm 0.9 \%$ for acetate were significantly smaller $(P<0.05)$ than for alanine $(17.7 \pm$ $0.3 \%$ ) (Figure 1). Decomposition to $\mathrm{CO}_{2}$ was greater for alanine $(74.0 \pm 0.8 \%)$ than for acetate $(60.1 \pm 0.9 \%)$ and glucose $(27.8 \pm$ $1.1 \%)$. Incorporation into microbial biomass $\left({ }^{N} C_{\mathrm{B}}\right)$, calculated with Equations (2) and (3), was significantly greater for glucose $(45.5 \pm 1.2 \%)$ than for alanine $(1.3 \pm 0.9 \%)$. The data suggest that acetate incorporation into microorganisms was less than $1 \%$. However, no satisfactory calculation of acetate sorption was possible, because of the sub-optimal Freundlich fit to the measured data at $10 \mu \mathrm{M}$.

Because a quasi-equilibrium for all three LMWOS was reached after about 200 minutes, the mixing period in the second experiment was set to this time.

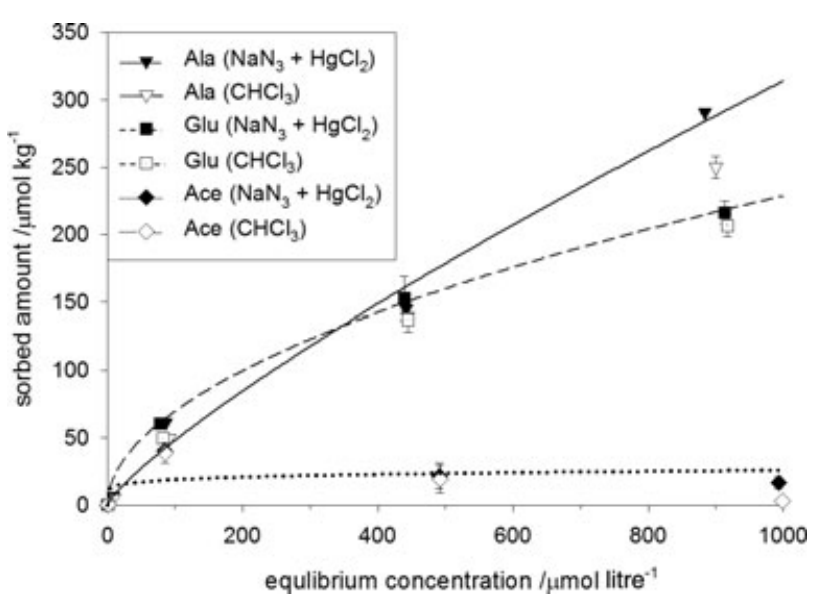

Figure 2 Sorption isotherms fitted by Freundlich equation to experimental points (means $\pm \mathrm{SE}, n=3$ ) for alanine (solid line), glucose (dashed line) and acetate (dotted line).

\section{Effect of LMWOS concentration on sorption and microbial uptake}

Up to concentrations of $100 \mu \mathrm{M}$, the Freundlich sorption isotherms for all the three investigated substances were in the same range (Figure 2); at equilibrium concentrations of 500 and $1000 \mu \mathrm{M}$, however, acetate sorption was much less than that for glucose and alanine. In fact, acetate sorption apparently decreased with increasing soil solution concentration. This pattern is not explainable with the Freundlich model.

The distribution of ${ }^{14} C$ from the added LMWOS between soil solution $\left({ }^{N} C_{\mathrm{L}}\right)$, soil $\left({ }^{N} C_{\mathrm{M}}\right)$ and the 'decomposed to $\mathrm{CO}_{2}$ (Respir)' pool strongly depended on the LMWOS added and their concentration (Figure 3). For all three substances, the absolute and relative values of ${ }^{14} C$ in non-sterilized solution $\left({ }^{N} C_{\mathrm{L}}\right)$ increased with increasing added amounts. In contrast, microbial incorporation and decomposition to $\mathrm{CO}_{2}$ differed for the three substances: The respiration from alanine ( $74 \%$ at $10 \mu \mathrm{M}$ to $35 \%$ at $1000 \mu \mathrm{M})$ and from acetate $(60-10 \%)$ decreased with increasing LMWOS concentrations. Conversely, decomposition of glucose to $\mathrm{CO}_{2}$ increased from $22 \pm 2 \%$ at $0.01 \mu \mathrm{M}$ to $26 \pm 1 \%$ at $1000 \mu \mathrm{M}$. The large percentages of the calculated sorbed amount $\left({ }^{N} C_{\mathrm{S}}\right)$ at very small concentrations $(\leq 10 \mu \mathrm{M})$ reflect the sub-optimal fit of the sorption isotherms in this concentration

Table 2 Experimentally fitted Freundlich parameters ( $\mathrm{m}_{\exp }, k_{f, \exp }$ ) describing the physicochemical sorption of LMWOS (Equation (2))

\begin{tabular}{|c|c|c|c|c|c|c|}
\hline Substance & \multicolumn{2}{|c|}{ Experimental data } & \multicolumn{4}{|c|}{ Data from 'two-stage one-rate' model } \\
\hline Alanine & $0.81 \pm 0.11$ & $1.13 \pm 0.81$ & 1.3 & 0.442 & 0.0784 & 0.99 \\
\hline Glucose & $0.52 \pm 0.02$ & $6.47 \pm 0.96$ & 0.58 & 0.53 & 0.0084 & 0.74 \\
\hline Acetate & $0.14 \pm 0.17$ & $10.09 \pm 10.19$ & - & - & - & - \\
\hline
\end{tabular}

The parameters determined by the 'two-stage one-rate' model ( $k_{f}, \mathrm{f}, \alpha$, Equation (5)) describing the dynamics of the sorption process, and the modelling efficiency EF for modelled fit (Equation (7)) for a concentration of $10 \mu \mathrm{M}$ under sterile conditions. The model was not fitted to the data for the acetate addition as its sorption was instantaneous (i.e. faster than 1 minute at the first sampling). 


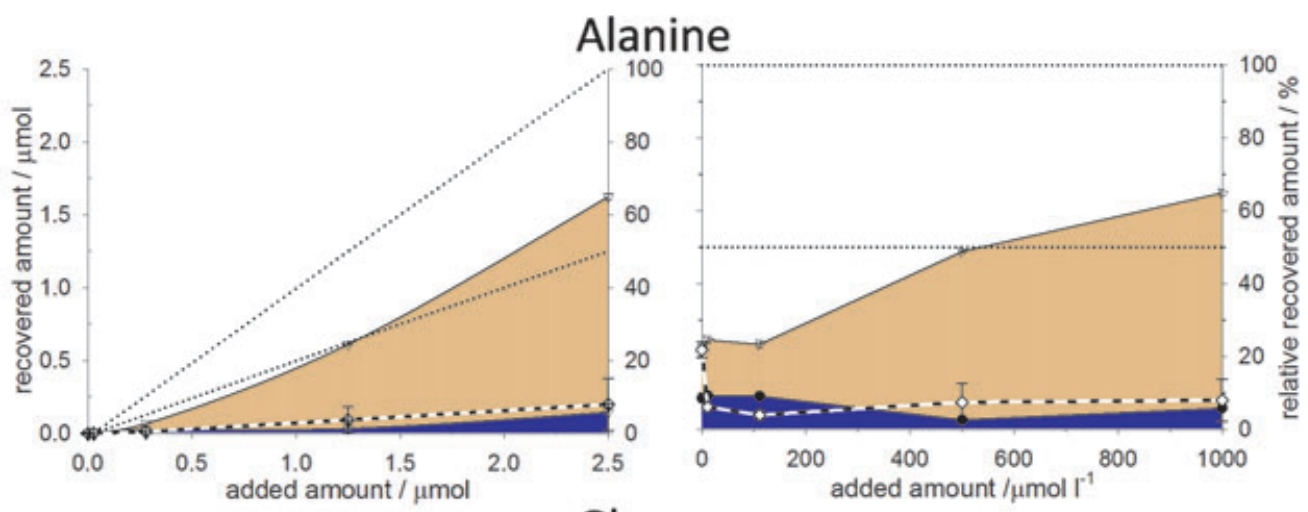

Glucose

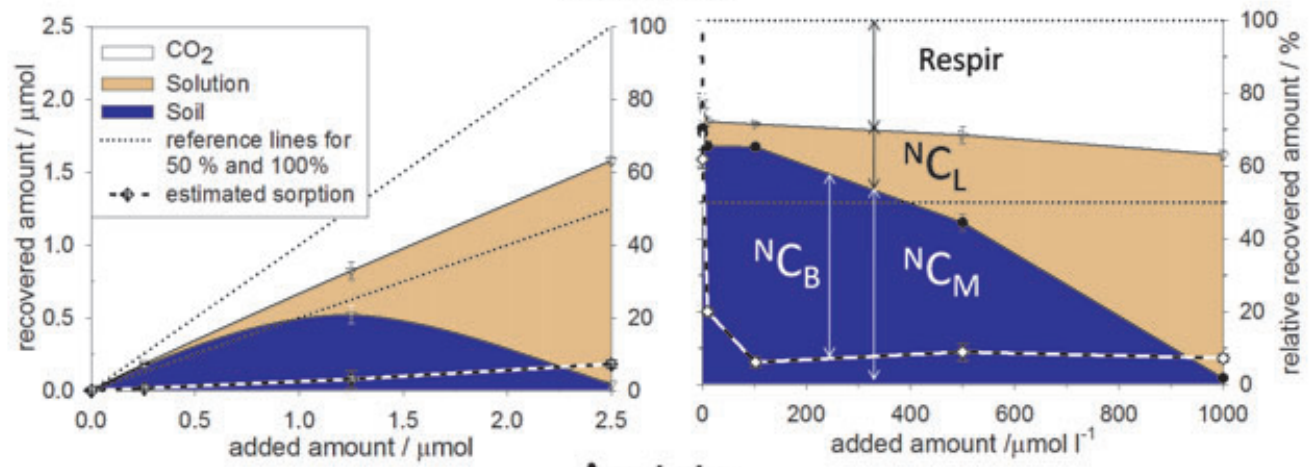

Acetate
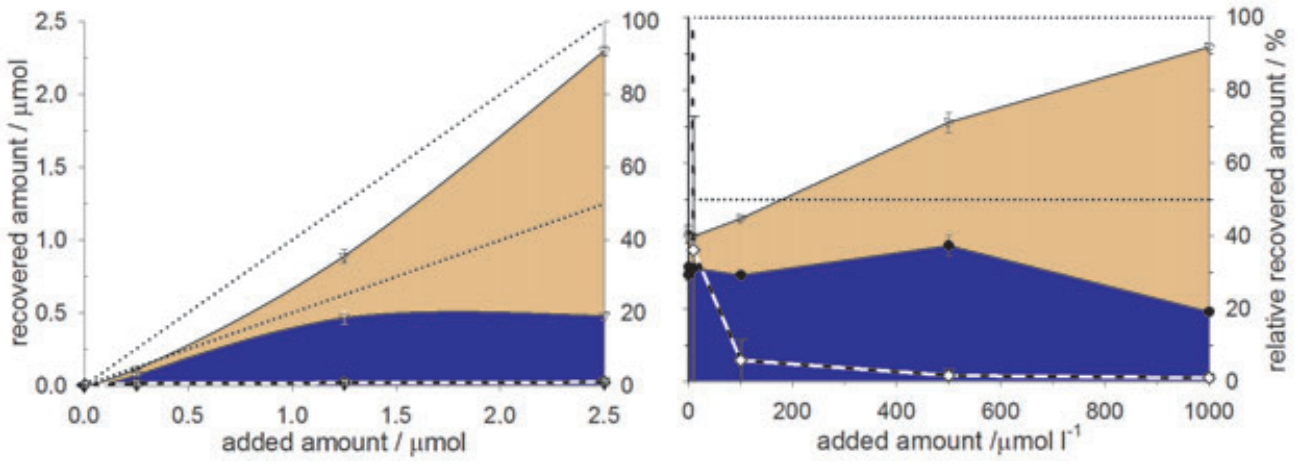

Figure 3 Effect of added LMWOS concentration in soil solution on absolute (left-hand-side graphs, $\mu \mathrm{M}$ ) and relative (right-hand-side graphs, \% of ${ }^{14} \mathrm{C}$ input) distribution of alanine (top), glucose (middle) and acetate (bottom) between soil solution $\left({ }^{N} C_{\mathrm{L}}\right)$, soil $\left({ }^{N} C_{\mathrm{M}}\right)$ and the 'decomposed to $\mathrm{CO}_{2}(\mathrm{Respir})$ ' pool, $(n=3$, means $\pm \mathrm{SE})$. In addition, the calculated sorbed amount $\left({ }^{N} C_{\mathrm{S}}\right.$, dashed line) is given (from Equation (2)). Subtracting ${ }^{N} C_{\mathrm{S}}$ from ${ }^{N} C_{\mathrm{M}}$ gives the amount of ${ }^{14} \mathrm{C}$ incorporated into microbial biomass $\left({ }^{N} C_{\mathrm{B}}\right.$, from Equation (3)). The legend applies to all sub-plots in the Figure.

range. Apart from this, the calculated absorbed amount in non-sterilized samples $\left({ }^{N} C_{\mathrm{S}}\right)$ was smaller than the total amount found in soil $\left({ }^{N} C_{\mathrm{M}}\right)$, except for the maximal concentrations (alanine $>500 \mu \mathrm{M}$ and glucose at $1000 \mu \mathrm{M})$. In general, the percentage of ${ }^{14} C$ in microbial biomass $\left({ }^{N} C_{\mathrm{B}},(\%)\right)$ decreased with increasing added LMWOS amounts (Figure 3, right-hand-side graphs).

Differences in the distribution of LMWOS after addition of $100 \mu \mathrm{M}$ under sterile and non-sterile conditions were minor (Figure 4): more glucose $(24.8 \pm 0.7 \%)$ than alanine $(22.8 \pm$ $1.2 \%)$ and acetate $(18.1 \pm 1.2 \%)$ was sorbed onto the soil matrix. Under non-sterile conditions, the distributions of glucose and alanine contrasted with each other. Sodium acetate was in an intermediate position: decomposition to $\mathrm{CO}_{2}$ was significantly greater for alanine $(76.7 \pm 1.1 \%)$ than for acetate $(55.2 \pm 0.9 \%)$ and glucose $(28.5 \pm 1.5 \%)$. In contrast, ${ }^{14} \mathrm{C}$ in soil $\left({ }^{N} C_{\mathrm{M}}\right)$ decreased significantly from glucose $(65.8 \pm 2.8 \%)$ to acetate $(29.3 \pm 0.8 \%)$ and alanine $(9.1 \pm 0.5 \%)$. This difference reflects incorporation into microbial biomass rather than sorption (Figure 2): microbial incorporation was greater for glucose $(59.8 \pm 1.2 \%)$ than for acetate $(23.4 \pm 5.9 \%)$ and alanine $(5.2 \pm 2.8 \%)$. 


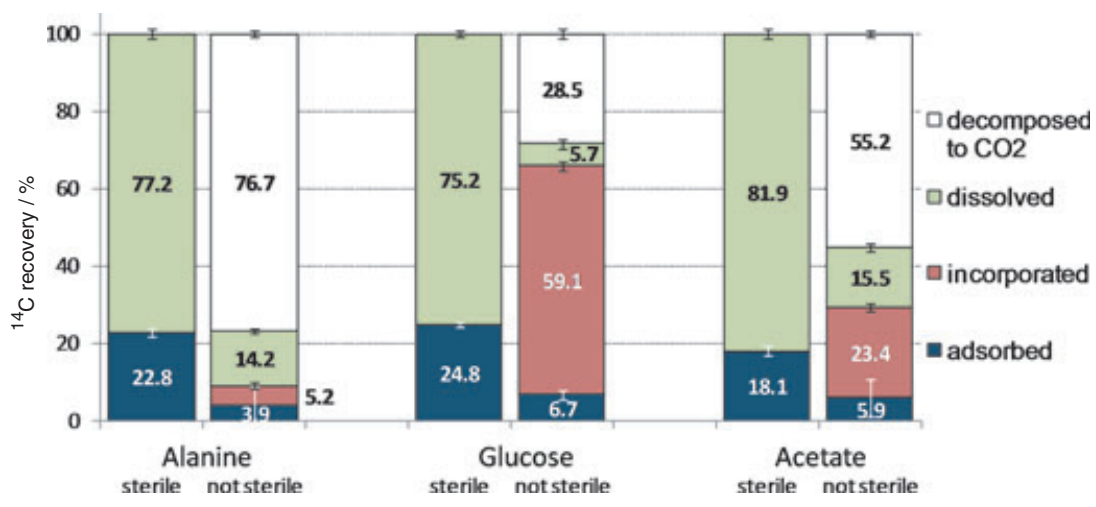

Figure $4{ }^{14} \mathrm{C}$ recovery from alanine, glucose and acetate in sterile samples (left-hand columns) and non-sterile samples (right-hand columns) at $100 \mu \mathrm{M}$ of added substances after 300 minutes. Sterile samples are divided into soil ('absorbed', $\left.C_{\mathrm{S}}\right)$ and solution $\left(C_{\mathrm{L}}\right)$. Recovery from non-sterile soil is divided into 'adsorbed' $\left({ }^{N} C_{\mathrm{S}}\right)$ and 'incorporated into microbial biomass' $\left({ }^{N} C_{\mathrm{B}}\right) .{ }^{14} \mathrm{C}$ not recovered in non-sterilized soil corresponds to $\mathrm{CO}_{2}$ produced by complete decomposition of the LMWOS. The decrease in the sorbed amount in the presence of microorganisms shows how strong microbial uptake outcompetes sorption. Data for soils sterilized by $\mathrm{CHCl}_{3}$ or $\mathrm{HgCl}_{2} / \mathrm{NaN}_{3}$ are averaged. Therefore, $n=6$ for sterilized, and 3 for non-sterilized samples. Means are given \pm SE.

For alanine, absolute respiration and the calculated amount sorbed increased constantly with increasing concentration (Figure 3, left-hand-side graphs). For glucose and acetate, this was the case only up to $500 \mu \mathrm{M}\left(1.25 \mu \mathrm{mol} \mathrm{g}^{-1}\right.$ soil $)$.

As $1.25 \mu \mathrm{mol} \mathrm{g}-1 \quad(500 \mu \mathrm{M})$ glucose was added, ${ }^{14} \mathrm{C}$ in soil $\left({ }^{N} C_{\mathrm{M}}\right)$ was $0.52 \pm 0.03 \mu \mathrm{mol} \mathrm{g}-1$ (41.8\%). ${ }^{N} C_{\mathrm{M}}$ decreased to $0.04 \pm 0.01 \mu \mathrm{mol} \mathrm{g}^{-1}(1.8 \%)$ when $2.5 \mu \mathrm{mol} \mathrm{g}-1(1000 \mu \mathrm{M})$ glucose was added. Thus, ${ }^{N} C_{\mathrm{M}}$ at $1000 \mu \mathrm{M}$ was even smaller than the amount calculated as the amount adsorbed $\left({ }^{N} C_{\mathrm{S}}\right)$. Clearly, in this case, the equilibrium between the solution and sorbed phases had not yet been reached.

The absolute amounts of acetate recovered in soil increased for additions of up to $1.25 \mu \mathrm{mol} \mathrm{g}{ }^{-1}$ to values around $0.47 \mu \mathrm{mol}$. Of this, ${ }^{N} C_{\mathrm{B}}$ was by far greater $(0.45 \mu \mathrm{mol})$ than ${ }^{N} C_{\mathrm{S}}(0.02 \mu \mathrm{mol})$.

\section{Discussion}

\section{Rate of LMWOS microbial uptake}

The short half-life of glucose in non-sterilized soil solution (1-2 minutes) agrees with the results that Hill et al. (2008) obtained with fresh soil. Consequently, our experimental data reflect a realistic situation in soil solution. The removal of acetate and alanine from non-sterile soil solution was as fast as that of glucose. The half-lives of acetate and alanine (minutes) were much shorter than reported in the literature (hours), for example by Jones \& Shannon (1999) for amino acids or by Jones (1998) for carboxylates. This results from the much smaller LMWOS concentrations that we used in the present study $(10 \mu \mathrm{M}$ compared with $5 \mathrm{~mm}$ ). Turnover at lower concentrations is faster and more complete at concentrations below $1 \mathrm{~mm}$ than above this concentration, probably because of saturation of transport mechanisms into microbial cells. Thus, Jones \& Hodge (1999) found that amino acid decomposition and relative $\mathrm{CO}_{2}$ production peaked at $500 \mu \mathrm{M}$. Nguyen \& Guckert (2001) proved that the turnover can be even faster at smaller concentrations $(0.01 \mu \mathrm{g} \mathrm{C}$ glucose $\mathrm{g}^{-1}$ soil): $96.4 \%$ was taken up by microorganisms within 1 hour, of which $8.7 \%$ was respired to $\mathrm{CO}_{2}$ and therefore $91.3 \%$ was incorporated into microbial biomass. This rapid uptake is possible because no enzymes are necessary to transport the substance through the bacteria's cell walls (Jones, 1999).

Shaking the samples increased the contact between microorganisms and LMWOS. Thus, more LMWOS were used by microorganisms in a shorter time than in the incubation experiments reported by Kuzyakov \& Demin (1998). Note that the half-lives in our study refer to conditions in soil solution: most other studies did not directly monitor the removal from soil solution, but relied on the evolution of $\mathrm{CO}_{2}$ from the added labelled substances. Therefore, their results refer rather to half-lives in microbial biomass, which were notably longer than those in soil solution.

Only a few studies have compared LMWOS of different groups (such as carbohydrates, amino acids, carboxylic acids and nucleic bases) under similar experimental conditions: Kuzyakov \& Demin (1998) showed that, under identical experimental conditions, glycine decomposed faster than glucose. Jones \& Edwards (1998) found that the half-life of citric acid was significantly longer than that of glucose. This did not reflect a slower decomposition of citrate but a stronger sorption of the triple-charged citrate molecule by synthetic ferric hydroxide or 'mixed clay subsoil'. We used acetate, which has only one carboxylic group. Therefore, its sorption characteristics and its bioavailability are less reduced by sorption to the soil matrix.

\section{Sorption of LMWOS}

Glucose was probably retained in the soil matrix of sterilized samples by sorption, although no clear mechanisms for sugar sorption have yet been suggested (Kuzyakov \& Jones, 2006). Any loss of glucose from the solution via precipitation can be ruled out because glucose concentrations were far below saturation $(2.6 \mathrm{M})$. 
Kuzyakov \& Jones (2006) found no microbial decomposition of glucose in samples sterilized either with $50 \mathrm{~mm} \mathrm{HgCl}_{2}$ or $\mathrm{NaN}_{3}$. The combination of these two sterilizing agents, as used in our approach, should have been at least equally efficient. For glucose (and for alanine) the soil solution concentrations could be described very well with the 'two-stage one rate' sorption model. Modelling efficiencies for glucose (0.74) and for alanine (0.99) suggest that these two LMWOS were bound to a sorbent that can be divided into two sub-domains. According to the model, the LMWOS concentration at the first sub-domain (outer surfaces of soil aggregates) is in immediate equilibrium with the concentration in solution. The sorption to the second sub-domain (that is to less accessible surfaces) is described by a rate-limited approach (Equation (5)). Such a two-phase character of sorption has been suggested by Jones et al. (2003) for LMW organic acids. They argued that for plant nutrient uptake only the first phase and for pedogenetic processes only the second phase might be important. The present experiment indicates that microorganisms can compete with sorption in both sub-domains. Firstly, both subdomains quickly achieve equilibrium (maximum 400 minutes). Secondly, equilibrium between absorbed and dissolved LMWOS was reached much faster in the non-sterilized treatments with alanine and glucose. If significant sorption had taken place after the rapid uptake by the microorganisms, then a further slow decrease in solution concentrations should have been observed.

Sorption of high-molecular-weight organic substances was reported to be instantaneous (Celis et al., 2005) and much faster than microbial uptake (incorporation and respiration). For LMWOS, we found evidence for this statement only in the case of acetate: sorption was completed within 1 minute, while microbial uptake then still continued. For glucose and alanine, in contrast, equilibrium between sorbed and dissolved amount took 1 hour. Microbial uptake of the two LMWOS was much faster (half-life: 1-3 minutes) than sorption.

Sorption of acetate $(18.1 \%$ at $100 \mu \mathrm{M},<5 \%$ at $1000 \mu \mathrm{M})$ was less than that usually reported for other LMW carboxylates such as oxalate, citrate or malate ( $>60 \%$, Jones, 1998; Ström et al., 2001). This result is confirmed by Angeles et al. (2006), who found 'no sorption' of acetic acid at $1.05 \mathrm{~mm}$. Less sorption of acetate compared with other carboxylates has been frequently described (e.g. Jones \& Brassington, 1998; van Hees et al., 2003). Monocarboxylic acetate is less well sorbed to the soil matrix, and stability constants for complexes with $\mathrm{Fe}$ or $\mathrm{Al}$ in solution are far smaller than for polycarboxylates such as citrate or oxalate (Jones et al., 2003; Guppy et al., 2005). Consequently, Jones \& Brassington (1998) found, for acetate in several Welsh and US-American soils, similar sorption isotherms to that shown in Figure 2.

\section{Effect of concentration on distribution of the three LMWOS after 200 minutes}

To compare the concentration-related fates of substances in soil, we selected the period of 200 minutes after addition; at this time, the distribution between all pools was nearly finished at all concentrations.

Alanine. A smaller percentage of added alanine decomposed to $\mathrm{CO}_{2}$ with increasing concentration, as observed in this experiment, was also found by Jones (1999) and Jones \& Hodge (1999): the former reported that, in the range from 100 to $10 \mathrm{~mm}, 65-80 \%$ of amino acids (glutamate, glycine and lysine) were incorporated into microbial biomass within 24 hours and only $20-35 \%$ were decomposed to $\mathrm{CO}_{2}$. The study carried out by Jones (1999) showed that even within 100 hours the ${ }^{14} \mathrm{CO}_{2}$ evolution from a $5 \mathrm{~mm}$ amino acid solution did not exceed $40 \%$ of the added ${ }^{14} \mathrm{C}$. In combination with our data, this suggests that when concentrations are small $(<0.5 \mathrm{~mm})$ amino acids are used in a catabolic pathway and decomposed to $\mathrm{CO}_{2}$ by maintenance processes. When concentrations increase to $0.5-1 \mathrm{~mm}$, additional amino acids are predominantly used in an anabolic pathway and incorporated into growing microbial cells. Calculations based on data from Werth et al. (2006) show that additions of $0.5 \mathrm{~mm}$ alanine correspond to about $15-20 \%$ of microbial carbon. For concentrations above $500 \mu \mathrm{M},{ }^{14} \mathrm{C}$ in non-sterilized soil $\left({ }^{N} C_{\mathrm{M}}\right)$ was only half the amount calculated as the sorbed amount by the Freundlich equation $\left({ }^{N} C_{\mathrm{S}}\right)$. Clearly, microorganisms took up the adsorbed alanine. This uptake continued for 200 minutes after alanine addition, demonstrating that the equilibrium between the sorbed phase and solution had not yet been reached. Microorganisms took up alanine not only from the solution, but also effectively desorbed alanine from sites for amino acids. While the preferred uptake of alanine as a nitrogen source is explicable, its extensive decomposition to $\mathrm{CO}_{2}$ instead of incorporation is surprising. This reflects the different pathways of carbon derived from the first position (carboxylic group) or from the second position (alkyl-amino group), where the carbon is directly connected to nitrogen (Fokin et al., 1994; Kuzyakov, 1997). Similar, fast utilization of carbon from the carboxylic group compared with that from the alkyl-amino group was recently shown for acetate (Fischer \& Kuzyakov, 2010).

Glucose. $\mathrm{CO}_{2}$ evolution increased from $23 \%$ at $0.1 \mu \mathrm{M}$ to $38 \%$ at $1000 \mu \mathrm{M}$ (Figure 3). A greater percentage of glucose decomposition with increasing glucose concentration has been frequently described (Nguyen \& Guckert, 2001; Schneckenberger et al., 2008). Bremer \& Kuikman (1994) interpreted this finding as 'metabolic arrest' in microbial cells at small glucose concentrations. In the same way, Hill et al. (2008) argued that at small concentrations, glucose- $\mathrm{C}$ is stored in a transitional pool (metabolic arrest) and not decomposed to $\mathrm{CO}_{2}$. Under this condition the microorganisms are able to incorporate but not to decompose glucose.

While the percentage of decomposition to ${ }^{14} \mathrm{CO}_{2}$ increased with increasing concentrations, the percentage of microbial incorporation decreased. This result agrees with Schneckenberger et al. (2008), who found, at glucose concentrations greater than $2.6 \mu \mathrm{g} C^{\circ} \mathrm{g}^{-1}$ soil (i.e. $0.036 \mu \mathrm{mol}$ glucose $\mathrm{g}^{-1}$, corresponding to approximately $14 \mu \mathrm{M}$ in our experiment), - a far lower use 
efficiency (i.e. less $C$ incorporated into microbial biomass and more $C$ decomposed to $\mathrm{CO}_{2}$ ). This is in the same range as in our experiment (between 10 and $100 \mu \mathrm{mol}$ glucose $1^{-1}$ (1.8 to $180 \mu \mathrm{g} \mathrm{C} \mathrm{g}^{-1}$ soil)).

Acetate. In a similar way to alanine but in contrast to glucose, the percentage of acetate decomposition decreased with increasing concentration. The reason for more acetate in non-sterilized soil was a greater incorporation by microorganisms; sorption was less important. In agreement with van Hees et al. (2002), our results suggest that at concentrations above $500 \mu \mathrm{M}$, acetate is preferentially used for incorporation into microbial biomass (anabolism) rather than decomposition to $\mathrm{CO}_{2}$ (catabolism). In contrast, Jones (1998) stated that most carboxylates are predominantly decomposed to $\mathrm{CO}_{2}(60 \%)$ instead of being incorporated into microbial biomass $(40 \%)$. Unlike malic and citric acid, acetate is not part of the respiratory cycle. For this reason, its decomposition might be arrested compared with the other carboxylates.

The large percentage of acetate that remained in soil solution at $1000 \mu \mathrm{M}$ indicates that the 200-minute period was insufficient for the microorganisms to use all available acetate. In contrast to concentrations of $10 \mu \mathrm{M}$, where acetate was decomposed as fast as alanine and glucose (Figure 1), at $1000 \mu \mathrm{M}$ acetate decomposition was slower than that of the other two LMWOS. After the end of the experiment (200 minutes) a considerable part of the acetate was incorporated but not (yet) decomposed to $\mathrm{CO}_{2}$. Concordantly, Jones \& Hodge (1999) found that $\mathrm{CO}_{2}$ evolution from decomposition of three amino acids at concentrations from 100 to $1000 \mu \mathrm{M}$ continued for 24 hours.

\section{Conclusions}

The direct analysis of the ${ }^{14} \mathrm{C}$ label in soil matrix and solution instead of monitoring the ${ }^{14} \mathrm{CO}_{2}$ evolution from labelled substances made it possible to evaluate concurrent physico-chemical (sorption) and microbial processes and to determine intrinsic LMWOS half-lives in soil solution. This evaluation of concurrent processes of LMWOS transformation such as sorption, microbial incorporation and decomposition to $\mathrm{CO}_{2}$, showed a strong dependence on the duration of the experiment and the concentration of the added substance.

The main distribution of LMWOS between the incorporated, decomposed and dissolved ${ }^{14} \mathrm{C}$ pools was finished after 30 minutes. This shows the extremely fast disappearance of LMWOS from soil solution. For alanine and glucose, microbial uptake was more than 10 times faster than sorption.

At small concentrations (up to $100 \mu \mathrm{M}$ ), alanine, glucose and acetate undergo different predominant metabolic pathways. While alanine and acetate are mainly decomposed to $\mathrm{CO}_{2}$, most of the glucose $\mathrm{C}$ was incorporated into microbial biomass.

For all the three investigated LMWOS, the composition in the pools investigated changed fundamentally depending on concentration of the added material $(10-500 \mu \mathrm{M})$. Glucose utilization changed from preferred incorporation to decomposition to $\mathrm{CO}_{2}$. Conversely, at greater concentrations, alanine and acetate were preferentially incorporated into microbial biomass.

We conclude that the fate of LMWOS in soil is predominantly controlled by microbial uptake and utilization. Physico-chemical processes such as sorption are less important. Partitioning between pools strongly depends on LMWOS concentration.

\section{Acknowledgements}

We thank the Deutsche Forschungsgemeinschaft for funding.

\section{References}

Angeles, O.R., Johnson, S.E. \& Buresh, R.J. 2006. Soil solution sampling for organic acids in rice paddy soils. Soil Science Society of America Journal, 70, 48-56.

Biernath, C., Fischer, H. \& Kuzyakov, Y. 2008. Root uptake of $\mathrm{N}$-containing and $\mathrm{N}$-free low molecular weight organic substances by maize: a ${ }^{14} \mathrm{C} /{ }^{15} \mathrm{~N}$ tracer study. Soil Biology \& Biochemistry, 40, 2237-2245.

Bremer, E. \& Kuikman, P. 1994. Microbial utilization of ${ }^{14} C$ [U] glucose in soil is affected by the amount and timing of glucose additions. Soil Biology \& Biochemistry, 26, 511-517.

Celis, R., Real, M., Hermosin, M.C. \& Cornejo, J. 2005. Sorption and leaching behaviour of polar aromatic acids in agricultural soils by batch and column leaching tests. European Journal of Soil Science, 56, 287-297.

De Cristofaro, A., He, J.Z., Zhou, D.H. \& Violante, A. 2000. Adsorption of phosphate and tartrate on hydroxy-aluminum-oxalate precipitates. Soil Science Society of America Journal, 64, 1347-1355.

Fischer, H. \& Kuzyakov, Y. 2010. Sorption, microbial uptake and decomposition of acetate in soil: transformations revealed by positionspecific ${ }^{14} \mathrm{C}$ labeling. Soil Biology \& Biochemistry, 42, 186-192.

Fischer, H., Meyer, A., Fischer, K. \& Kuzyakov, Y. 2007. Carbohydrate and amino acid composition of dissolved organic matter leached from soil. Soil Biology \& Biochemistry, 39, 2926-2935.

Fischer, H., Eckhardt, K.-U., Meyer, A., Neumann, G., Leinweber, P., Fischer, K. \& Kuzyakov, Y. 2010. Rhizodeposition of maize: shortterm carbon budget and composition. Journal of Plant Nutrition \& Soil Science 173, 67-79.

Fokin, A.D., Knyazev, D.A. \& Kuzyakov, Y. 1994. Incorporation of ${ }^{14} \mathrm{C}$ and ${ }^{15} \mathrm{~N}$ amino acids and nucleic bases into humus and the turnover of atomic-molecular composition. Eurasian Soil Science, 26, 24-34.

Guppy, C.N., Menzies, N.W., Moody, P.W. \& Blamey, F.P.C. 2005. Competitive sorption reactions between phosphorous and organic matter in soil: a review. Australian Journal of Soil Research, 43, 189-202.

van Hees, P.A.W., Jones, D.L. \& Godbold, D.L. 2002. Biodegradation of low molecular weight organic acids in coniferous forest podzolic soils. Soil Biology \& Biochemistry, 34, 1261-1272.

van Hees, P.A.W., Vinogradoff, S.I., Edwards, A.C., Godbold, D.L. \& Jones, D.L. 2003. Low molecular weight organic acid adsorption in forest soils: effects on soil solution concentrations and biodegradation rates. Soil Biology \& Biochemistry, 35, 1015-1026.

Hill, P., Farrar, J. \& Jones, D.L. 2008. Decoupling of microbial glucose uptake and mineralization in soil. Soil Biology \& Biochemistry, 40, 616-624.

IUSS Working Group WRB. 2007. World Reference Base for Soil Resources 2006, First Update 2007. World Soil Resources Reports No. 103. FAO, Rome. 
Jones, D.L. 1998. Organic acids in the rhizosphere - a critical review. Plant \& Soil, 205, 25-44.

Jones, D.L. 1999. Amino acid biodegradation and its potential effects on organic nitrogen capture by plants. Soil Biology \& Biochemistry, 31, $613-622$.

Jones, D.L. \& Brassington, D. 1998. Sorption of organic acids in acid soils and its implications in the rhizosphere. European Journal of Soil Science, 49, 447-455.

Jones, D.L. \& Edwards, A. 1998. Influence of sorption on the biological utilization of two simple carbon substrates. Soil Biology \& Biochemistry, 30, 1895-1902.

Jones, D.L. \& Hodge, A. 1999. Biodegradation kinetics and sorption reactions of three differently charged amino acids in soil and their effects on plant organic nitrogen availability. Soil Biology \& Biochemistry, 31, $1331-1342$.

Jones, D.L. \& Shannon, D. 1999. Mineralization of amino acids applied to soils: impact of soil sieving, storage, and inorganic nitrogen additions. Soil Science Society of America Journal, 63, 1199-1206.

Jones, D.L., Dennis, P., Owen, A. \& van Hees, P. 2003. Organic acid behavior in soils - misconceptions and knowledge gaps. Plant \& Soil, 248, 31-41.

Kraffczyk, I., Trolldenier, G. \& Beringer, H. 1984. Soluble root exudates of maize: influence of potassium supply and rhizosphere microorganisms. Soil Biology \& Biochemistry, 16, 315-322.

Kuzyakov, Y.V. 1997. The role of amino acids and nucleic bases in turnover of nitrogen and carbon in soil humic fractions. European Journal of Soil Science, 48, 121-130.

Kuzyakov, Y. \& Demin, V. 1998. $\mathrm{CO}_{2}$ efflux by rapid decomposition of low molecular organic substances in soils. Sciences of Soils, 3, $11-22$.
Kuzyakov, Y. \& Jones, D.L. 2006. Glucose uptake by maize roots and its transformation in the rhizosphere. Soil Biology \& Biochemistry, 38, $851-860$

Loague, K. \& Green, R. 1991. Statistical and graphical methods for evaluating solute transport models: overview and application. Journal of Contaminant Hydrology, 7, 51-73.

Nannipieri, P., Ascher, J., Ceccherini, M.T., Loretta, L., Giacomo, P. \& Giancarlo, R. 2003. Microbial diversity and soil functions. European Journal of Soil Science, 54, 655-670.

Nguyen, C. \& Guckert, A. 2001. Short-term utilisation of ${ }^{14}$ C-[U]glucose by soil microorganisms in relation to carbon availability. Soil Biology \& Biochemistry, 33, 53-60.

Pegoraro, R.F., Silva, I.R., Novais, R.F., Mendonca, E.S., Alvarez, V.H.V., Nunes, F.N., Fonseca, F.M. \& Smyth, T.J. 2005. Diffusive flux of cationic micronutrients in two oxisols as affected by low-molecularweight organic acids and cover-crop residue. Journal of Plant Nutrition \& Soil Science, 168, 334-340.

Schneckenberger, K., Demin, D., Stahr, K. \& Kuzyakov, Y. 2008. Microbial utilization and mineralization of $\left[{ }^{14} \mathrm{C}\right]$ glucose added in six orders of concentration to soil. Soil Biology \& Biochemistry, 40, 1981-1988.

Streck, T., Poletika, N.N., Jury, W.A. \& Farmer, W.J. 1995. Description of simazine transport with rate-limited, two-stage, linear and nonlinear sorption. Water Resources Research, 31, 811-822.

Ström, L., Owen, A.G., Godbold, D.L. \& Jones, D.L. 2001. Organic acid behaviour in a calcareous soil: sorption reactions and biodegradation rates. Soil Biology \& Biochemistry, 33, 2125-2133.

Werth, M., Subbotina, I. \& Kuzyakov, Y. 2006. Three-source partitioning of $\mathrm{CO}_{2}$ efflux from soil planted with maize by $\mathrm{C}-13$ natural abundance fails due to inactive microbial biomass. Soil Biology \& Biochemistry, 38, 2772-2781. 